\title{
ITPKC as a Prognostic and Predictive Biomarker of Neoadjuvant Chemotherapy for Triple Negative Breast Cancer
}

\author{
Masanori Oshi ${ }^{1,2}{ }^{\oplus}$, Stephanie Newman ${ }^{1,3}$, Vijayashree Murthy ${ }^{1}$, Yoshihisa Tokumaru ${ }^{1,4}{ }^{\oplus}$, \\ Li Yan ${ }^{5}$, Ryusei Matsuyama ${ }^{2}$, Itaru Endo ${ }^{2}$ and Kazuaki Takabe 1,2,3,6,7,8,9,*(D) \\ 1 Breast Surgery, Department of Surgical Oncology, Roswell Park Comprehensive Cancer Center, Buffalo, \\ New York, NY 14263, USA; masa1101oshi@gmail.com (M.O.); snewman5@buffalo.edu (S.N.); \\ Vijayashree.Murthy@RoswellPark.org (V.M.); Yoshihisa.Tokumaru@roswellpark.org (Y.T.) \\ 2 Department of Gastroenterological Surgery, Yokohama City University Graduate School of Medicine, \\ Yokohama 236-0004, Japan; ryusei@yokohama-cu.ac.jp (R.M.); endoit@med.yokohama-cu.ac.jp (I.E.) \\ 3 Department of Surgery, Jacobs School of Medicine and Biomedical Sciences, State University of New York, \\ Buffalo, New York, NY 14263, USA \\ 4 Department of Surgical Oncology, Graduate School of Medicine, Gifu University, 1-1 Yanagido, \\ Gifu 501-1194, Japan \\ 5 Department of Biostatistics \& Bioinformatics, Roswell Park Comprehensive Cancer Center, Buffalo, \\ New York, NY 14263, USA; li.yan@roswellpark.org \\ 6 Division of Digestive and General Surgery, Niigata University Graduate School of Medical and Dental \\ Sciences, Niigata 951-8520, Japan \\ 7 Department of Breast Surgery, Fukushima Medical University School of Medicine, \\ Fukushima 960-1295, Japan \\ 8 Department of Breast Surgery and Oncology, Tokyo Medical University, Tokyo 160-8402, Japan \\ 9 Roswell Park Comprehensive Cancer Center, Elm \& Carlton Streets, Buffalo, New York, NY 14263, USA \\ * Correspondence: kazuaki.takabe@roswellpark.org; Tel.: +1-716-845-5540; Fax: +1-716-845-1668
}

Received: 3 September 2020; Accepted: 22 September 2020; Published: 25 September 2020

Simple Summary: Inositol 1,4,5-trisphosphate 3-kinase C (ITPKC) gene is a negative regulator of $\mathrm{T}$ cell activation and is a proven promoter of Kawasaki disease. Given the critical role of immune response in breast cancer, we aimed to determine the clinical relevance of ITPKC expression in breast cancer. ITPKC expression was highest in triple negative breast cancer, associated with its survival, and was its independent prognostic factor. Although high ITPKC expression was not associated with immune function nor with any immune cell fraction, low ITPKC triple negative breast cancer was significantly associated with activated cell proliferation, and they achieved a significantly rate in pathological complete response (disappearance of tumor) after neoadjuvant chemotherapy. To the best of our knowledge, this is the first report to demonstrate that ITPKC gene expression may be useful as a prognostic and predictive biomarker in triple negative breast cancer.

\begin{abstract}
Triple negative breast cancer (TNBC) is the most aggressive subtype of breast cancer with higher mortality than the others. Pathological complete response (pCR) to neoadjuvant chemotherapy (NAC) is considered as a surrogate to predict survival. Inositol 1,4,5-trisphosphate 3-kinase C (ITPKC) is a negative regulator of $\mathrm{T}$ cell activation, and reduction in ITPKC function is known to promote Kawasaki disease. Given the role of tumor infiltrating lymphocytes in NAC and since TNBC has the most abundant immune cell infiltration in breast cancer, we hypothesized that the ITPKC expression level is associated with NAC response and prognosis in TNBC. The ITPKC gene was expressed in the mammary gland, but its expression was highest in breast cancer cells among other stromal cells in a bulk tumor. ITPKC expression was highest in TNBC, associated with its survival, and was its independent prognostic factor. Although high ITPKC was not associated with immune function nor with any immune cell fraction, low ITPKC significantly enriched cell proliferation-related gene sets in
\end{abstract}


TNBC. TNBC with low ITPKC achieved a significantly higher pCR rate after NAC. To the best of our knowledge, this is the first report to demonstrate that ITPKC gene expression may be useful as a prognostic and predictive biomarker in TNBC.

Keywords: biomarker; breast cancer; gene expression; metastasis; survival; ITPKC; TNBC; treatment response

\section{Introduction}

Breast cancer represents the most common malignancy and leading cause of cancer related morbidity and mortality all over the world, accounting for $30 \%$ of all new cancer diagnoses in females [1]. Triple negative breast cancer (TNBC) accounts for $10-15 \%$ of invasive cancers with an aggressive clinical course, early relapses and overall poor prognosis [2,3]. This is not only because TNBC lacks treatable molecular targets such as estrogen receptor (ER) or human epidermal growth factor receptor 2 (HER2) like the other subtypes [4], but also because TNBC is known to be highly proliferative [5] with a high expression of Ki67, the most commonly used marker of cell proliferation [6]. TNBC is known to relate to several proliferation-related pathways $[7,8]$. Our group has previously reported that TNBC has high activity of the E2F pathway [9] and G2M checkpoint pathway [10], both of which are essential components of the cell cycle and critical for cell proliferation.

Some TNBCs respond to neoadjuvant chemotherapy (NAC) (chemotherapy prior to definite operation), and pathological complete response (pCR) following NAC is now considered a surrogate to predict the long-term clinical outcome [11]. Given the aggressive clinical behavior and limited therapeutic options, a predictive biomarker for NAC response is needed not only to improve the efficacy of treatment, but also to reduce chemotherapy-related toxicity and improve quality of life.

Tumor infiltrating lymphocytes (TIL) have recently proven to play a major role in cancer biology and that includes breast cancer. One such example would be the significant role played by CD8+ effector $\mathrm{T}$ cells in the adaptive immune response through their production of interferon gamma $(I F N-\gamma)$ and initiation of cytolytic activity [12]. This is especially true for TNBC which has an abundance of TIL [13]. Although it lacks clinical application, TIL has been reported as both a prognostic and predictive biomarker for $\mathrm{pCR}$ following NAC in TNBC, but not in hormone-positive breast cancer [14-16]. In PD-L1-positive metastatic TNBC, a pembrolizumab (anti-PD-1 antibody) combined group demonstrated a significantly higher $\mathrm{PCR}$ rate than chemotherapy alone $[17,18]$. Atezolizumab (anti-PD-L1 antibody) with Nab-pacritaxel was shown to have a significantly longer progression-free survival than Nab-paclitaxel alone in PD-L1-positive locally advanced and metastatic TNBC in the Impassion 130 study [19]. KEYNOTE-522 is a phase III study of NAC combined with pembrolizumab in patients with TNBC [20]. These reports suggest that, currently, $P D-L 1$ is used as a predictive biomarker for immune checkpoint inhibition, however, it is also known that there are many patients who respond to treatment without PD-L1 expression.

Our group has been reporting the clinical relevance of the tumor immune microenvironment (TIME) in breast cancer using bioinformatic algorisms with transcriptomic data, such as Gene Set Enrichment Analysis (GSEA) [21-23], CYBERSORT [24-26] and xCell [27-29].

Inositol 1,4,5-trisphosphate 3-kinase C (ITPKC), encoded by the ITPKC gene on chromosome 19q13.2, is known to be associated with Kawasaki disease, a pediatric disorder characterized by hyperactive $\mathrm{T}$ cells affecting the medium-sized arteries producing multi-systemic vasculitis predominantly seen in a Far East Asian population [30-33]. Recently, ITPKC expression was linked with cervical cancer carcinogenesis [34]. Overexpression of ITPKC was shown to increase microvascular adhesion of circulating colon cancer cells before hepatic metastasis formation [35]. Given that ITPKC is a negative regulator of T cells, we hypothesized that a low level of ITPKC expression is associated with enhanced cancer immunity, thus is associated with better response to NAC and survival in TNBC. 


\section{Results}

2.1. ITPKC Is Expressed in Mammary Gland, but Its Expression Was Highest in Breast Cancer Cells among Other Stromal Cells in a Bulk Breast Tumor

In order to identify which cells express ITPKC within a bulk breast cancer tumor, we analyzed ITPKC expression in tumor cells, B cells, stromal cells, myeloid cells and $\mathrm{T}$ cells using single-cell sequencing data of primary breast cancer (GSE75688) utilizing the same method we previously reported [36]. As shown in Figure 1, ITPKC was significantly expressed higher in breast cancer cells compared with stroma or immune cells.

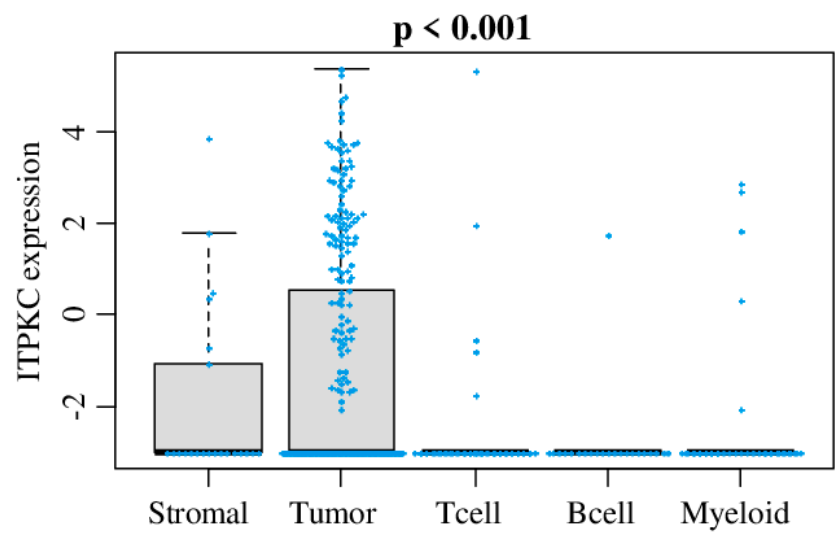

Figure 1. ITPKC gene expression among cells in the tumor microenvironment. Boxplots of the ITPKC gene expression by cancer cells, stromal cells, T cells, B cells and myeloid cells in single-cell sequencing data of primary breast cancer in GSE75688. One-way ANOVA test was used to calculate $p$ values. Tukey-type boxplots show median and inter-quartile level values.

\subsection{ITPKC Is Highly Expressed in TNBC and Is Associated with Its Worse Prognosis}

We studied whether ITPKC expression is associated with clinical aggressiveness of breast cancer in The Cancer Genome Atlas (TCGA) cohort (Figure 2A). There was no significant difference in ITPKC expression by the American Joint Committee on Cancer (AJCC) cancer staging (Stage I-IV) and Nottingham grading system (Grade I, II and III) in a TCGA breast invasive carcinoma (BRCA) cohort ( $p=0.681$ and $p=0.824$, respectively). ITPKC expression was significantly higher in TNBC compared to the other subtypes (ER-positive/HER2-negative, HER2-positive) ( $p=0.027)$.

In order to seek the clinical relevance of ITPKC expression, we performed survival analyses of the whole breast cancer cohort (Whole), and ER-positive/HER2-negative, TNBC and HER2-positive subtypes by Kaplan-Meier analyses of overall survival (OS), disease-free survival (DFS) and disease-specific survival (DSS) in the TCGA and DFS alone in the GSE25066 cohort (Figure 2B). Top quartile expression of ITPKC was defined as the high group, and the others as the low group. There was no association between any survival outcome and ITPKC expression in ER-positive/HER2-negative and HER2-positive subtypes in the TCGA, which were validated in the GSE25066 cohort. The HER2-positive subtype was not analyzed in the GSE25066 cohort because the cohort size was too small. High ITPKC expression was significantly associated with worse OS, DFS and DSS in TNBC (Figure 2B, all $p<0.001$ ). This result was validated in the GSE25066 cohort that demonstrated a significant association of high ITPKC expression and worse DFS in TNBC (Figure 2B, DFS: $p=0.004$ in TNBC). ITPKC expression was not associated with any survival outcome in the Whole cohort of TCGA, but high expression associated with worse DFS in the Whole cohort of GSE25066 (Figure 2B, DFS: $p=0.024$ ). This is most likely a reflection of the disproportional ratio of TNBC in GSE25066 $(178 / 467=38 \%)$ compared to the TCGA $(159 / 1064=15 \%)$ or to the general population $(10-15 \%)$. These findings suggest that high expression of ITPKC is significantly associated with worse survival in TNBC, but not with the other subtypes. 
A

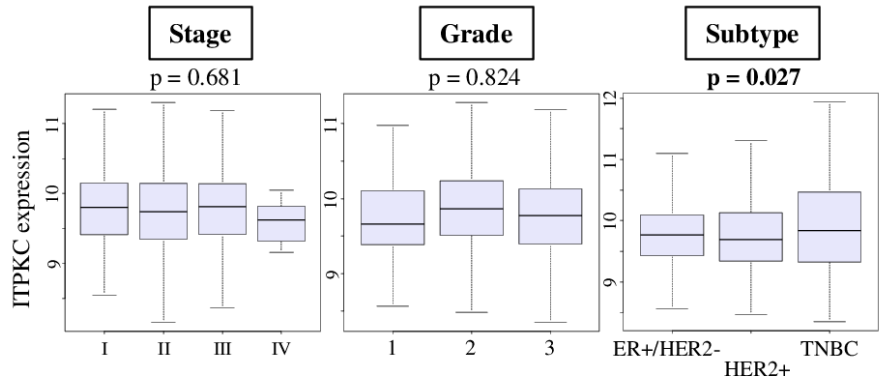

B
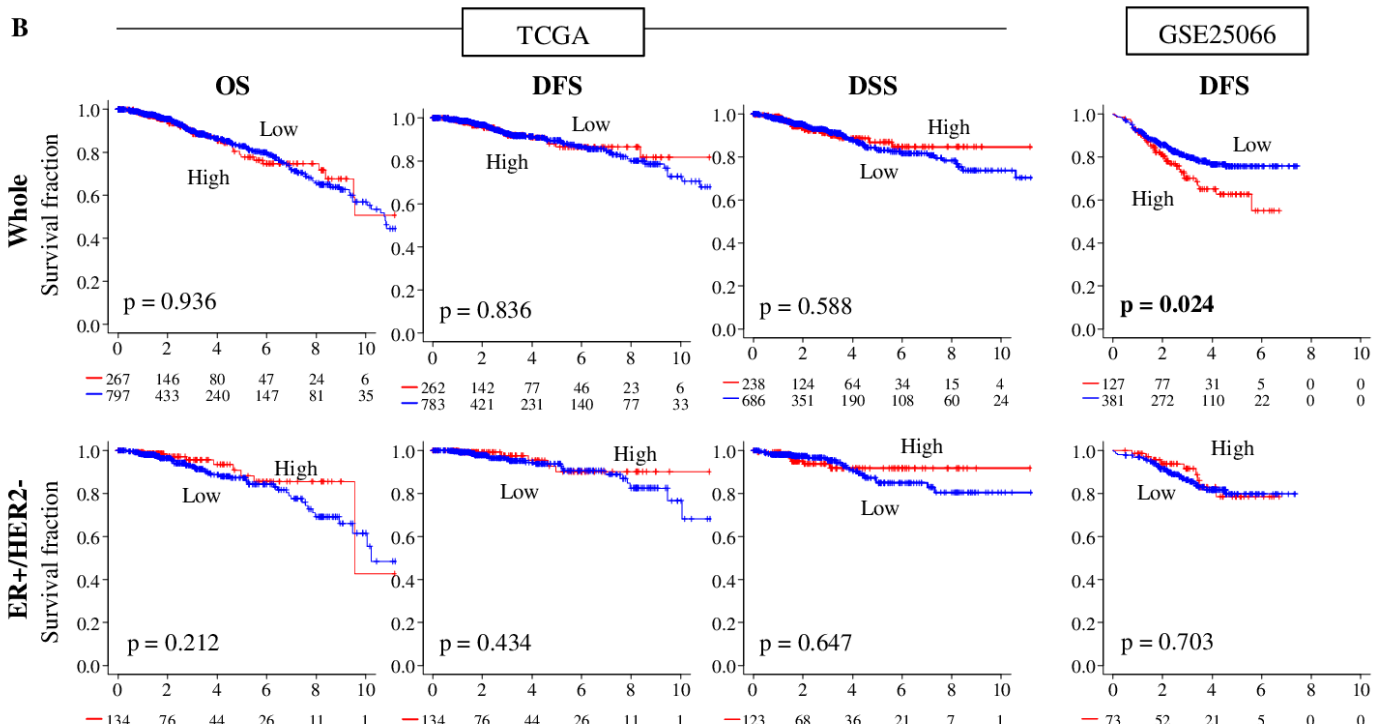

$\begin{array}{cccccc}-127 & 772 & 31 & 5 & 0 & 0 \\ -381 & 272 & 110 & 22 & 0 & 0\end{array}$

$\begin{array}{lllllllllllllllll}-134 & 76 & 44 & 26 & 11 & 1 & -134 & 76 & 44 & 26 & 11 & 1 & -123 & 68 & 36 & 21 & 7 \\ -444 & 228 & 128 & 73 & 40 & 11 & -438 & 223 & 125 & 71 & 38 & 10 & -383 & 184 & 103 & 54 & 30\end{array}$
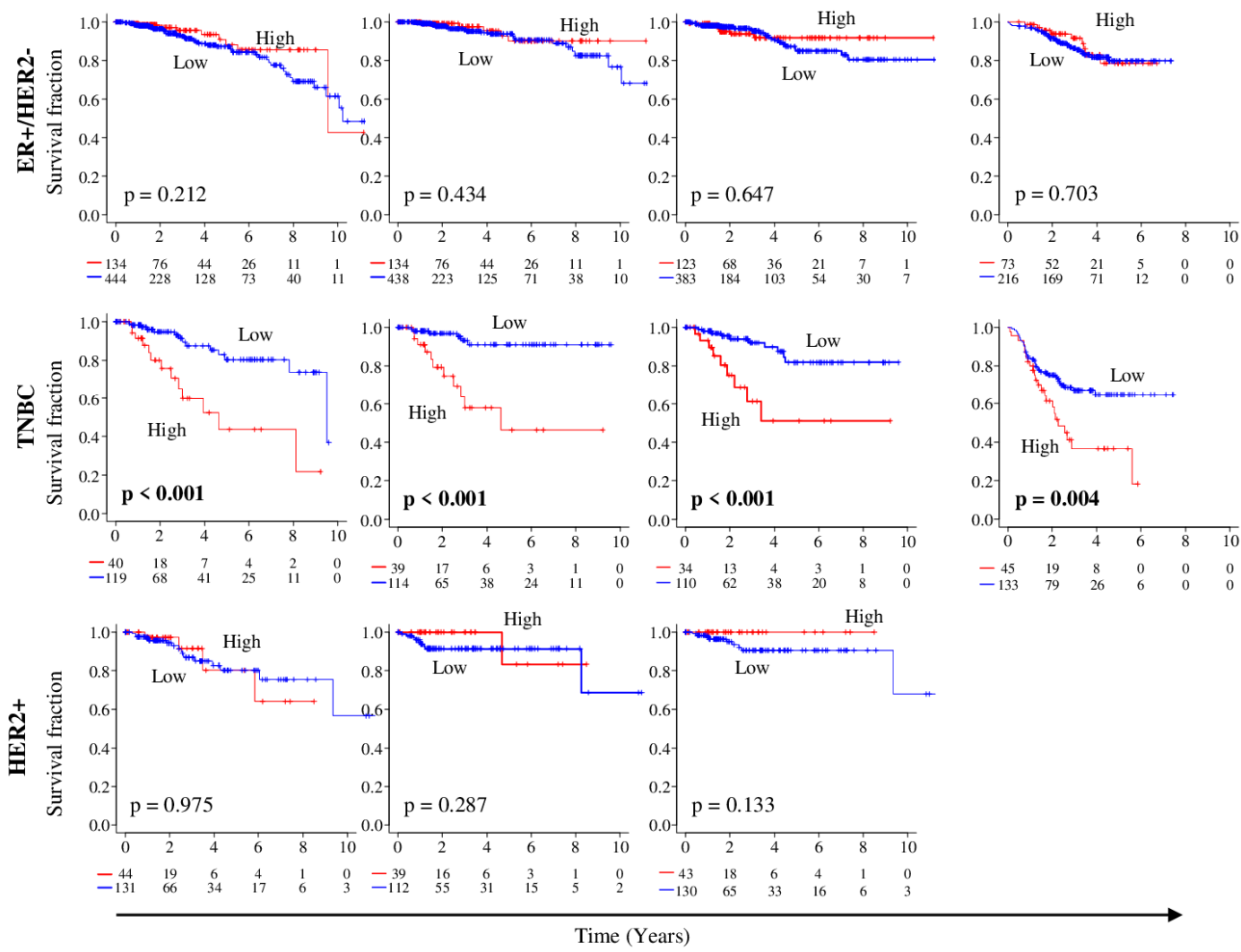

Figure 2. ITPKC gene expressions and clinical features including survival in the TCGA and GSE5066 breast cancer cohort. (A) Boxplots of the ITPKC expression by American Joint Committee on Cancer (AJCC) stage, Nottingham pathological grade and breast cancer subtype. One-way ANOVA test was used to calculate $p$ values. Tukey-type boxplots show median and inter-quartile level values. (B) Association between ITPKC expression and survival of breast cancer patients in the TCGA and GSE25066 cohorts. Overall survival (OS), disease-free survival (DFS) and disease-specific survival (DSS) of ITPKC expression low and high in whole breast cancer cohort (Whole), estrogen receptor-positive/human epidermal growth factor receptor 2-negative (ER+/HER2-), triple negative breast cancer (TNBC) and HER2+ in the TCGA cohort and DFS in the GSE25066 cohort. The top quartile was defined as the high-score group within each cohort. Log rank test was used to compare between two groups with Kaplan-Meier survival curves and to calculate $p$ values. 
2.3. There Was no Difference in Clinical Characteristics between Low-and High-ITPKC Expression Groups in TNBC of TCGA

To study the association between ITPKC expression and clinical characteristics in TNBC, we compared ITPKC levels with age at diagnosis, race and tumor, using the tumor size, lymph node, and metastasis (TNM) as well as cancer stage (Stages I-IV) classification based on the AJCC cancer staging system in the TCGA (Table 1) as well as in the GSE25066 cohort (Table S1). There was no statistically significant difference between the low- and high-ITPKC groups with any of the clinical characteristics analyzed in both cohorts.

Table 1. Clinical characteristics of low and high ITPKC expression in TNBC patients in the TCGA cohort.

\begin{tabular}{cccc}
\hline \multirow{2}{*}{ Clinical Variables } & ITPKC-Low & ITPKC-High & \multirow{2}{*}{$\boldsymbol{p}$-Value } \\
\cline { 2 - 3 } & $\boldsymbol{( n = 1 1 9 )}$ & $\boldsymbol{(} \boldsymbol{n}=\mathbf{4 0 )}$ & \\
\hline Age at diagnosis & & & 0.920 \\
Median & 55.0 & 52.5 & \\
IQR & $48-62$ & $44-66$ & \multirow{2}{*}{0.078} \\
Race & $75(63.0 \%)$ & $15(37.5 \%)$ & \\
White & $29(24.4 \%)$ & $25(62.5 \%)$ & \\
Black & $8(6.7 \%)$ & $0(0 \%)$ & \multirow{2}{*}{0.116} \\
Asian & & & \\
AJCC T-category & $28(23.5 \%)$ & $12(30.0 \%)$ & \\
T1 & $79(66.4 \%)$ & $20(50.0 \%)$ & \\
T2 & $10(8.4 \%)$ & $5(12.5 \%)$ & \\
T3 & $2(1.7 \%)$ & $3(7.5 \%)$ & \\
T4 & & & \\
AJCC N-category & $81(68.1 \%)$ & $24(60.0 \%)$ & \\
N- & $38(31.9 \%)$ & $16(40.0 \%)$ & \multirow{2}{*}{0.405} \\
N+ & & & \\
AJCC M-category & $104(87.4 \%)$ & $30(75.0 \%)$ & \\
M- & $1(0.8 \%)$ & $1(2.5 \%)$ & \multirow{2}{*}{0.078} \\
M+ & & & \\
Stage at diagnosis & $20(16.8 \%)$ & $8(20.0 \%)$ & \\
I & $82(68.9 \%)$ & $20(50.0 \%)$ & \\
II & $14(11.8 \%)$ & $10(25.0 \%)$ & \\
III & $1(0.8 \%)$ & $1(2.5 \%)$ & \\
IV &
\end{tabular}

AJCC: American Joint Committee on Cancer, IQR: interquartile range.

\subsection{ITPKC Expression Level Is an Independent Prognostic Factor for TNBC Survival}

We then performed univariate and multivariate Cox regression analyses in TNBC of the TCGA cohort to investigate whether the prognostic value of the ITPKC expression level is independent of various clinical factors. We found that the ITPKC level is independent of clinical factors (such as age, race and TNM status). In the univariate analysis of disease-specific survival (DSS) in the TCGA cohort, AJCC cancer staging categories $\mathrm{T}, \mathrm{N}$ and $\mathrm{M}$, and ITPKC expression level had a significant hazard ratio (HR) (Table 2). In multivariate analyses, $\mathrm{T}, \mathrm{N}$ and ITPKC were all found to be independent prognostic factors $(\mathrm{HR}=2.50,95 \%$ confidence interval $(\mathrm{CI})=1.17-5.34 ; p=0.018)$.

Table 2. Survival analyses of ITPKC expression and other factors in the TCGA cohort.

\begin{tabular}{ccccc}
\hline \multirow{2}{*}{ TCGA (DSS) } & \multicolumn{2}{c}{ Univariate } & \multicolumn{2}{c}{ Multivariate } \\
\cline { 2 - 5 } & HR (95\% CI) & $p$-Value & HR (95\% CI) & $p$-Value \\
\hline Age & $1.43(0.46-4.40)$ & 0.536 & & \\
Race (Caucasian vs. other) & $0.51(0.19-1.35)$ & 0.177 & & $<0.001^{*}$ \\
T (T3/4 vs. T1/2) & $7.16(2.62-19.59)$ & $<0.001^{*}$ & $2.46(0.59-10.19)$ & $0.002^{*}$ \\
N (N+ vs. N-) & $5.36(1.89-15.23)$ & $0.001^{*}$ & $15.42(3.72-63.86)$ & 0.631 \\
M (M+ vs. M-) & $9.43(2.13-41.71)$ & $0.003^{*}$ & $0.61(0.08-4.57)$ & $0.018^{*}$ \\
ITPKC expression level & $1.97(1.03-3.76)$ & $0.041^{*}$ & $2.50(1.17-5.34)$ & 0.05.
\end{tabular}

CI: confidence interval, DSS: disease-specific survival, HR: hazard ratio. ${ }^{*} p$-value $<0.05$. 
2.5. ITPKC Expression Level Was not Associated with Immune-Related Pathway nor with Immune Cell Infiltration in TNBC

Since ITPKC is a negative regulator of $\mathrm{T}$ cell activity [32], we expected that ITPKC expression is associated with an immune-related pathway. To test this hypothesis, we performed the Gene Set Enrichment Analyses (GSEA) of Hallmark gene sets in both the TCGA and GSE25066 cohorts (Figure 3A). Surprisingly, ITPKC expression did not enrich any immune-related Hallmark gene sets: interferon (IFN)- $\alpha$ response, IFN- $\gamma$ response, IL2-STAT5 signaling and inflammatory response, in neither of the cohorts.

A

$\begin{array}{ccccc}\text { IFN- } \alpha & \text { IFN- } \gamma & \text { IL2_STAT5 } & \text { Inflammatory } & \text { Angiogenesis } \\ \text { response } & \text { response } & \text { signaling } & \text { response } & \end{array}$
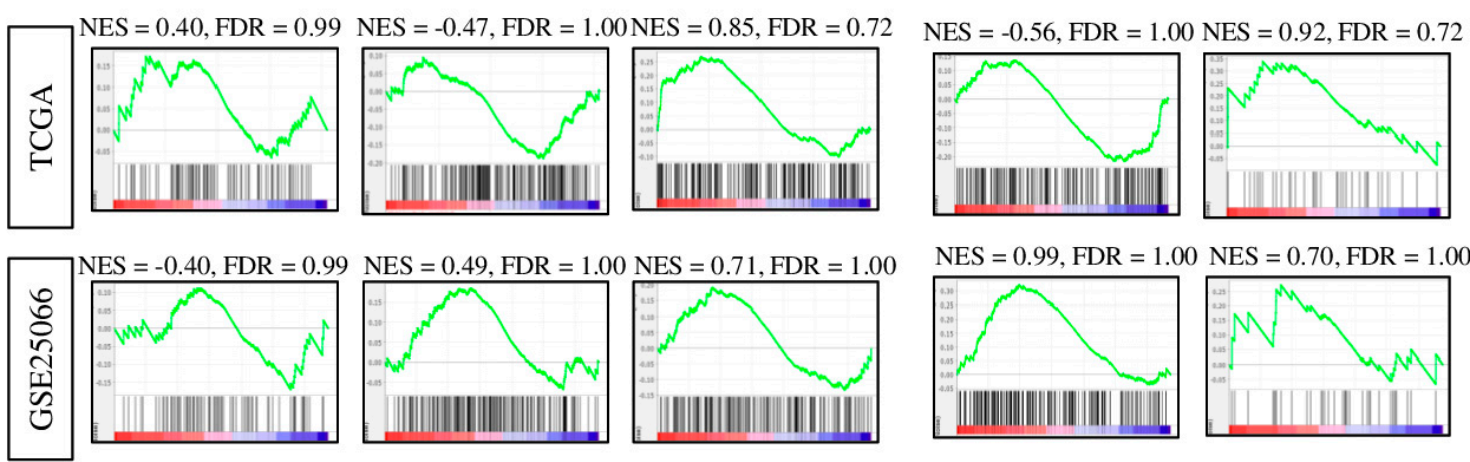

$\mathrm{NES}=0.99, \mathrm{FDR}=1.00 \mathrm{NES}=0.70, \mathrm{FDR}=1.00$

ITPKC High

Low

B
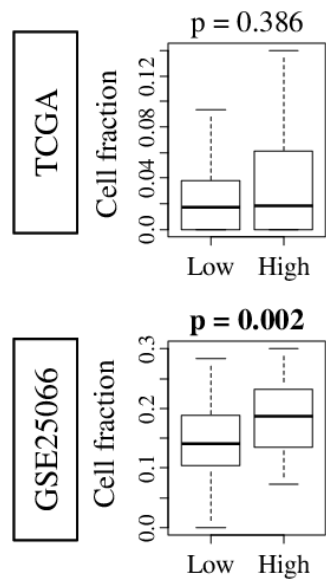

CD4 memory
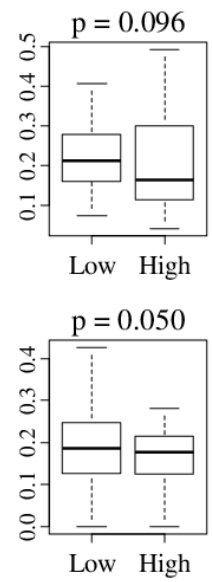

Th1
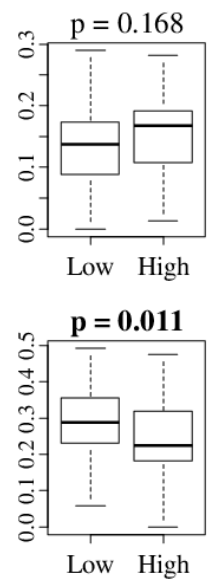

Th2

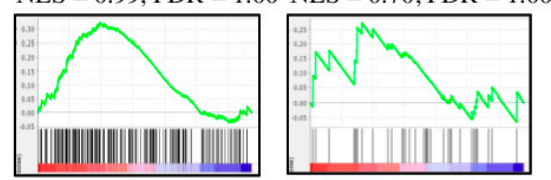

Figure 3. ITPKC gene expression and immune function and immune cell fraction with TNBC in the TCGA and GSE25066 cohorts. (A) Correlation plots of immune-related gene sets: interferon (IFN)- $\alpha$ and $\gamma$, IL2-STAT5 signaling, IL6/JAK/STAT3 signaling, inflammatory response and angiogenesis, with normalized enrichment score (NES) and false discovery rate (FDR). FDR $<0.25$ is considered to be statistically significant. (B) Boxplots of the comparison with CD8, CD4 memory, T helper type 1 cells (Th1), T helper type 2 cells (Th2) and regulatory T cell (Treg), by low and high ITPKC expression in both cohorts. The top quartile was defined as the high-score group within each TNBC cohort. One-way ANOVA test was used to calculate $p$ values. Tukey-type boxplots show median and inter-quartile level values.

Given the function of ITPKC to suppress T cells [32,37], it was of interest to investigate the association between ITPKC expression and immune cells composition utilizing the $\mathrm{xCell}$ algorithm. Again, we found that high-ITPKC expression tumors were not associated with any $\mathrm{T}$ cells fractions, 
including CD8 T cell, CD4 memory T cell, T helper 1 (Th1) and regulatory T cell, except for T helper 2 (Th2) cells, in the TCGA cohort (Figure 3B). A high-ITPKC tumor was significantly associated with a high fraction of CD8, regulatory T and a low fraction of Th1 in the GSE25066 cohort. These results combined, there was no immune cell fraction that was consistently associated with ITPKC expression levels in both cohorts, thus we concluded that there is no association between ITPKC expression and immune cell infiltration in TNBC.

\subsection{Low-ITPKC Expression Tumors Enriched Cell Proliferation-Related Gene Sets in TNBC}

To investigate why low-ITPKC expression TNBC is associated with better survival, we performed GSEA of the 50 Hallmark gene sets to low-ITPKC expression tumors. Low-ITPKC TNBC significantly enriched three out of five Hallmark cell proliferation-related gene sets: G2M checkpoint, E2F targets and mitotic signaling (Figure 4A; normalized enrichment score (NES) $=-1.83,-1.69,-1.92$, and FDR $=0.09,0.15,0.11$, respectively). These results were validated with the GSE25066 cohort (Figure 4A; NES $=-1.46,-1.49,-1.58$, and FDR $=0.16,0.16,0.12$, respectively). Low expression of ITPKC was significantly associated with high expression of MKI67, the most commonly used marker of cell proliferation in the clinical setting, in the TCGA cohort (Figure $4 \mathrm{~B}, p<0.001$ ). However, this was not validated with the GSE25066 cohort $(p=0.806)$. The proliferation score derived from a previous report [38] was significantly elevated in low-ITPKC expression TNBC $(p<0.001)$ (Figure 4C).

A G2M checkpoint

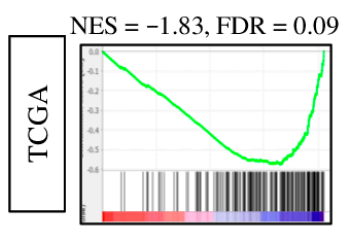

$\mathrm{NES}=-1.46, \mathrm{FDR}=0.16$

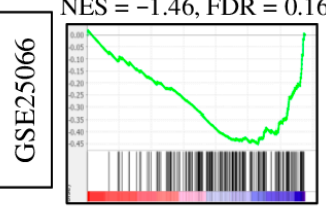

ITPKC High
E2F targets
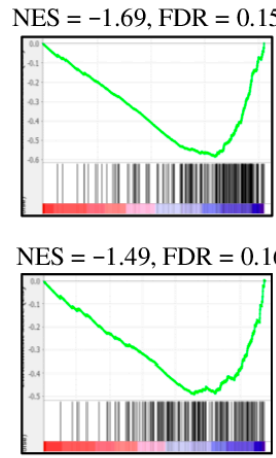

Mitotic signaling
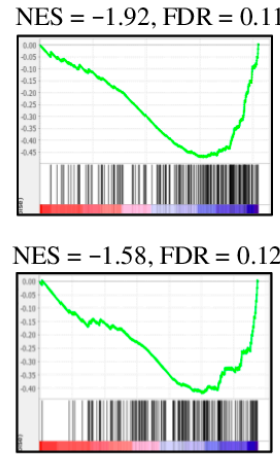
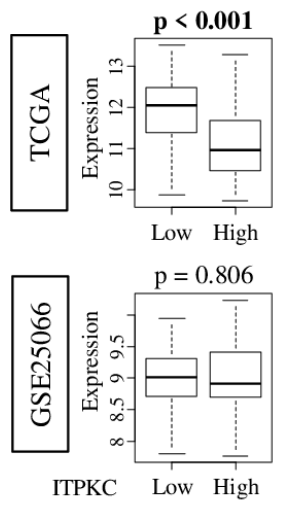

C
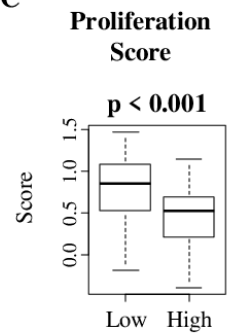

Figure 4. Hallmark gene sets with significant enrichment in low-ITPKC group of TNBC in both TCGA and GSE25066 cohorts. (A) Gene set enrichment plots along with NES and FDR of gene sets: G2M checkpoint, E2F targets and mitotic signaling. NES and FDR were determined with the classical GSEA method. (B) MKI67 gene expression in the low- and high-ITPKC expression groups of both cohorts. (C) Boxplots of proliferation score between low and high ITPKC expression in the TCGA cohort. The top quartile was defined as the high-score group within each cohort. One-way ANOVA test was used to calculate $p$ values. Tukey-type boxplots show median and inter-quartile level values.

2.7. Pathological Complete Response ( $p C R$ ) was Associate with Lower Expression of ITPKC and Low ITPKC Is Predictive of $p C R$ to Neoadjuvant Chemotherapy (NAC) in TNBC

It is well known that highly proliferative cancers are more likely to respond to cytotoxic chemotherapy $[9,10,39,40]$. Given our results that low-ITPKC expression TNBCs are highly proliferative, we hypothesized that they are associated with better NAC response. We found that patients who achieved pCR after NAC had significantly lower ITPKC expression in TNBC, but not in the ER-positive/Her2-negative subtype, consistently in two cohorts, GSE25066 and GSE20194 (Figure 5A; TNBC $p=0.015,0.004 ;$ ER-positive/Her2-negative $p=0.118,0.395$, respectively). 
A

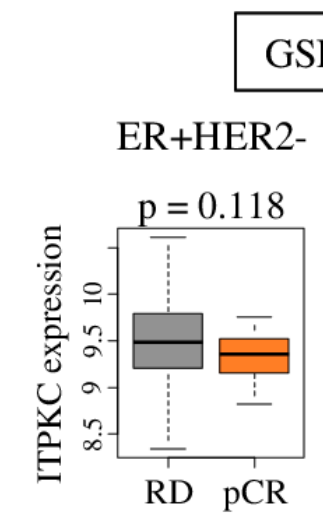

\section{GSE25066}

ER+HER2-

\section{GSE20194}
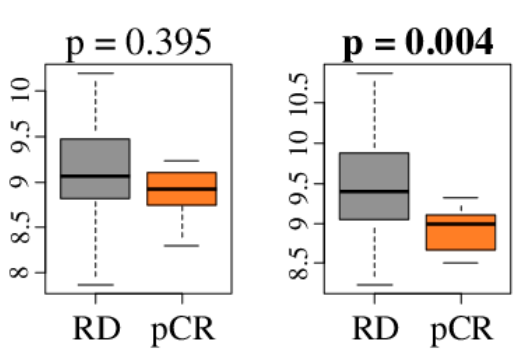

$\mathrm{pCR}$

口 $\mathrm{RD}$

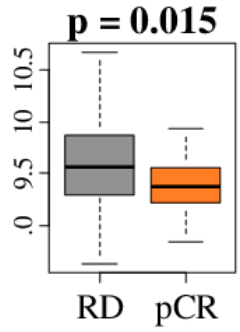

\section{GSE25066}

ER+HER2-

TNBC

B

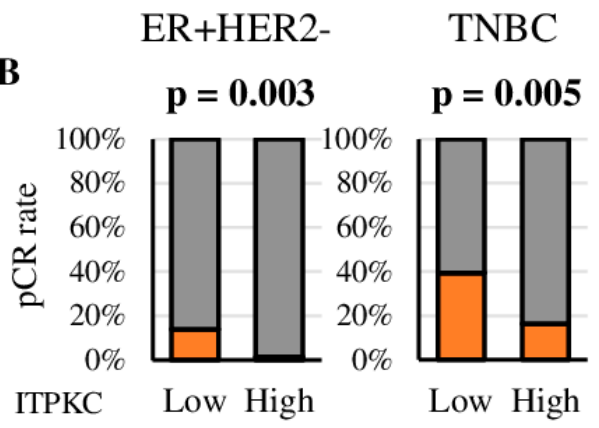

\section{GSE20194}

ER+HER2- $\quad$ TNBC

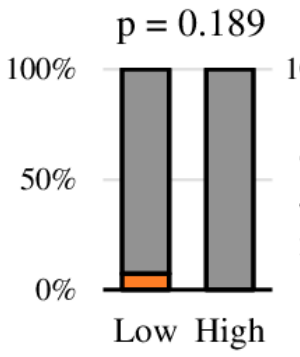

$\mathbf{p}=\mathbf{0 . 0 2 1}$

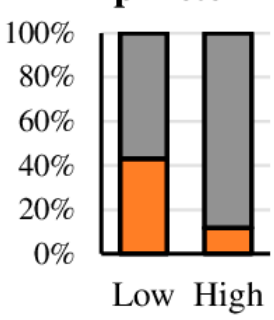

口 $\mathrm{pCR}$

口 RD

Figure 5. ITPKC gene expression and treatment response in ER+/HER2- and TNBC patients. (A) Boxplots of the ITPKC expression of residual disease (RD) and pathological complete response (pCR) after NAC in GSE25066 $(n=467)$ and GSE20194 $(n=197)$ cohorts. One-way ANOVA test was used to calculate $p$ values. (B) pCR rate after NAC by low and high ITPKC expression in ER+/HER2- and TNBC in same two cohorts. The top quartile was defined as the high-score group within each cohort. Fisher's exact test was used to calculate $p$ values.

We further found that TNBCs with low ITPKC expressions prior to NAC were significantly associated with an increased likelihood of achieving PCR compared to those with high ITPKC expression in GSE25066 ( $p=0.005)$, which was validated in GSE20194 ( $p=0.021)$ (Figure 5B). Only one cohort (GSE25066) revealed a similar association of low ITPKC expression and high rate of pCR in ER-positive/HER2-negative tumors $(p=0.002)$; however, this result was not validated in GSE20194 $(p=0.189)$. The above findings suggest that expression of ITPKC has a predictive role in neoadjuvant treatment response in TNBC.

\section{Discussion}

The ITPKC gene was highly expressed in the breast mammary gland, but its expression was found to be highest in breast cancer cells among other stromal cells in a bulk tumor. TNBC expressed the highest levels of ITPKC among subtypes. High ITPKC expression was significantly associated with worse survival in TNBC but not in the other subtypes. ITPKC expression was found to be an independent prognostic factor in TNBC. Although high ITPKC was not associated with immune function nor with any immune cell fraction, low ITPKC significantly enriched cell proliferation-related gene sets in TNBC. A low-ITPKC tumor was significantly associated with a high pCR rate in TNBC. To the best of our knowledge, this is the first report to demonstrate that ITPKC expression may be useful as both a prognostic and predictive biomarker in TNBC. 
ITPKC is one of the three isoenzymes of inositol 1,4,5-trisphosphate 3-kinase (ITPK) that phosphorylate inositol 1,4,5-trisphosphate (IP3), a key second messenger in many cell types [41]. ITPKC regulates immune responses [32], such as modulation of nuclear factor of activated T cells [42,43]. The biological impact of ITPKC on disease pathogenesis has been most widely studied in Kawasaki disease, Hirschsprung disease and more recently in cervical squamous cell carcinoma and colorectal malignancies with hepatic metastases [32,34,35,44]. In a study of 465 patients with cervical squamous cell carcinoma and 800 controls, Yang et al. found that the G/G genotype and G allele of the ITPKC rs28493229 polymorphism contributed to carcinogenesis of cervical cancer, whereas the $\mathrm{C} / \mathrm{G}$ genotype and $C$ allele protected against disease development [34]. Using random homozygous gene perturbation (RHGP) in combination with specific adhesion assays of cancer cells, expression changes of ITPKC were found to regulate hepatic microvascular adhesion of circulating colon cancer cells by overexpression in nonadherent cancer cell clones [35]. We were unable to find any study other than ours to report the association of ITPKC expression with cell proliferation in breast cancer.

A predictive biomarker to select responders to NAC is expected to maximize the treatment benefit, reduce toxicities and financial costs and improve patients' quality of life. Since NAC is known to be effective in highly proliferative cancer, we have previously focused on the generation of scores that reflect cell proliferation as biomarkers, that predict NAC response to breast cancer. We found that the E2F pathway plays a critical role in the cell cycle predicted NAC response in ER-positive/HER2-negative but not in TNBC patients [9]. We further found that the G2M checkpoint pathway is also critical in the cell cycle predicted NAC response in ER-positive/HER2-negative but not in TNBC patients [10]. We have established a four-gene score from the genes differentially expressed between the parental and lung metastasis cell lines that predicted NAC response in ER-positive/HER2-negative, and again, not in TNBC patients. In the current study, we found that ITPKC expression predicts the NAC response in TNBC with a single gene expression, which is far more clinically appreciable in terms of cost and simplicity. Genomic signature profiling, such as Oncotype Dx and MammaPrint, has been used in the clinical practice to predict the benefit of adjuvant chemotherapy in hormone-positive breast cancers. Since ITPKC expression predicts the NAC response of TNBC, it does not overlap with the existing genomic signature profiling. We cannot help but speculate that the ITPKC expression may have a clinical utility to be used for patient selection and as a predictive biomarker for NAC in TNBC.

Although we found a novel role of ITPKC expression in TNBC, this study is not free from limitations. First, our analysis is a retrospective study and limited in the measurement of gene expression. Secondly, our study was conducted by a bioinformatics approach alone. Although we have validated our findings using multiple cohorts in silico, in vivo and in vitro experimental approaches are needed to elucidate the mechanism as well as the causality of low expression of ITPKC and cell proliferation. Further, since we use publicly available multiple cohorts that are often from completely different sizes and backgrounds, the results may vary. Finally, in order to use ITPKC expression in TNBC management as both a predictive and prognostic biomarker, we need to analyze using quantitative polymerase.

In conclusion, we demonstrated that low ITPKC expression in TNBC was significantly associated with better survival and better response to NAC, which was not the case in the ER-positive/HER2-negative subtype. Thus, ITPKC expression may be useful as a prognostic and predictive biomarker in TNBC.

\section{Materials and Methods}

\subsection{Cohorts Used for Analyses}

Boxplots were generated using $\mathrm{R}$ version 4.0.1. Tumor RNA sequencing-based expression and clinical data for 1065 patients of The Cancer Genome Atlas (TCGA) breast cancer (BRCA) project [45] were obtained from the cBio Cancer Genomic Portal [46]. The TCGA was chosen because it is one of the largest cohorts with a full transcriptome that is attached to robust clinical information. Single-cell 
sequencing data of primary breast cancer were obtained from the studies of Chung et al. (GSE75688) [47]. Clinicopathologic and normalized microarray-based gene expression data were also obtained for the studies of Hatzis et al. (GSE25066; $n=467$ ) [48], Shi et al. (GSE20194; $n=248$ ) [49] and Noguchi et al. (GSE32646; $n=81$ ) [50] from the GEO repository (http://www.ncbi.nlm.nih.gov/geo). These cohorts were chosen because they have clinical response data after neoadjuvant chemotherapy that TCGA lacks. Gene expression levels in the TCGA, such as ITPKC, were directly obtained from the cBio Portal, and the average of the gene expression levels was used when there were multiple probes for a single gene in the gene expression microarray, which was transformed to $\log 2$ for analyses as we previously described [36,51]. In terms of survival data, overall survival (OS), disease-free survival (DFS) and disease-specific survival (DSS) were available in the TCGA, and DFS was available in the GSE25066 cohort.

\subsection{Cell Composition Fraction Estimation}

xCell, a computational algorithm, was used to estimate the cell score of a tumor from its gene expression profiles [52]. Calculated data were downloaded through the xCell website (https: //xcell.ucsf.edu/).

\subsection{Gene Set Expression Analyses}

Gene Set Enrichment Analyses (GSEA) software (Java version 4.0) [53] with MSigDb Hallmark was used [54] for gene set enrichment analysis, and a false discovery rate (FDR) of 0.25, as recommended by the GSEA software, was used to deem statistical significance as we previously reported $[23,27-29,36,55-61]$.

\subsection{Other}

Statistical analyses and data plotting were performed using R (version 4.0.1) or Microsoft Excel (version 16 for Windows). The value of 0.05 was the $p$ value cut-off for statistical significance. The Kaplan-Meier method with a log rank test was used for survival analysis. Two-tailed Fisher's exact tests or one-way ANOVA provided statistical comparisons between groups. Tukey-type boxplots demonstrate median and inter-quartile level values.

\section{Conclusions}

Although we did not see any correlation with immune cell number or activity, we found that low ITPKC gene expression was associated with highly proliferative activity in TNBC and hence better response to neoadjuvant chemotherapy.

Supplementary Materials: The following are available online at http://www.mdpi.com/2072-6694/12/10/2758/s1, Table S1: Clinical characteristics of low and high ITPKC expression in TNBC patients in the GSE25066 cohort.

Author Contributions: Conceptualization, I.E., K.T., M.O., R.M.; methodology, K.T., M.O., Y.T.; formal analysis, M.O.; writing—original draft preparation, M.O.; writing—review and editing, K.T., L.Y., S.N., V.M.; supervision, K.T.; project administration, K.T. All authors have read and agreed to the published version of the manuscript.

Funding: This work was supported by National Institutes of Health, USA grant R01CA160688 to K.T., and National Cancer Institute, USA cancer center support grant P30-CA016056 to Roswell Park Comprehensive Cancer Center (RPCCC).

Conflicts of Interest: The authors declare no conflict of interest. 


\section{Abbreviations}

$\begin{array}{ll}\text { AJCC } & \text { American Joint Committee on Cancer } \\ \text { DFS } & \text { disease-free survival } \\ \text { DSS } & \text { disease-specific survival } \\ \text { FDR } & \text { false discovery rate } \\ \text { GSVA } & \text { gene set variation analysis } \\ \text { METABRIC } & \text { Molecular Taxonomy of Breast Cancer International Consortium } \\ \text { NES } & \text { normalized enrichment score } \\ \text { OS } & \text { overall survival } \\ \text { pCR } & \text { pathological complete response } \\ \text { PFS } & \text { progression-free survival } \\ \text { TCGA } & \text { The Cancer Genome Atlas } \\ \text { TNBC } & \text { triple negative breast cancer }\end{array}$

\section{References}

1. Siegel, R.L.; Miller, K.D.; Jemal, A. Cancer statistics, 2020. CA Cancer J. Clin. 2020, 70, 7-30. [CrossRef] [PubMed]

2. Perou, C.M.; Sørlie, T.; Eisen, M.B.; van de Rijn, M.; Jeffrey, S.S.; Rees, C.A.; Pollack, J.R.; Ross, D.T.; Johnsen, H.; Akslen, L.A.; et al. Molecular portraits of human breast tumours. Nature 2000, 406, 747-752. [CrossRef] [PubMed]

3. Rakha, E.A.; El-Rehim, D.A.; Paish, C.; Green, A.R.; Lee, A.H.; Robertson, J.F.; Blamey, R.W.; Macmillan, D.; Ellis, I.O. Basal phenotype identifies a poor prognostic subgroup of breast cancer of clinical importance. Eur. J. Cancer 2006, 42, 3149-3156. [CrossRef] [PubMed]

4. De Laurentiis, M.; Cianniello, D.; Caputo, R.; Stanzione, B.; Arpino, G.; Cinieri, S.; Lorusso, V.; De Placido, S. Treatment of triple negative breast cancer (TNBC): Current options and future perspectives. Cancer Treat. Rev. 2010, 36 (Suppl. 3), S80-S86. [CrossRef]

5. Aleskandarany, M.A.; Green, A.R.; Benhasouna, A.A.; Barros, F.F.; Neal, K.; Reis-Filho, J.S.; Ellis, I.O.; Rakha, E.A. Prognostic value of proliferation assay in the luminal, HER2-positive, and triple-negative biologic classes of breast cancer. Breast Cancer Res. BCR 2012, 14, R3. [CrossRef]

6. Keam, B.; Im, S.A.; Lee, K.H.; Han, S.W.; Oh, D.Y.; Kim, J.H.; Lee, S.H.; Han, W.; Kim, D.W.; Kim, T.Y.; et al. $\mathrm{Ki}-67$ can be used for further classification of triple negative breast cancer into two subtypes with different response and prognosis. Breast Cancer Res. BCR 2011, 13, R22. [CrossRef]

7. Singh, S.; Kumar, S.; Srivastava, R.K.; Nandi, A.; Thacker, G.; Murali, H.; Kim, S.; Baldeon, M.; Tobias, J.; Blanco, M.A.; et al. Loss of ELF5-FBXW7 stabilizes IFNGR1 to promote the growth and metastasis of triple-negative breast cancer through interferon- $\gamma$ signalling. Nat. Cell Biol. 2020, 22, 591-602. [CrossRef]

8. Jiang, S.; Meng, L.; Chen, X.; Liu, H.; Zhang, J.; Chen, F.; Zheng, J.; Liu, H.; Wang, F.; Hu, J.; et al. MEX3A promotes triple negative breast cancer proliferation and migration via the PI3K/AKT signaling pathway. Exp. Cell Res. 2020, 112191. [CrossRef]

9. Oshi, M.; Takahashi, H.; Tokumaru, Y.; Yan, L.; Rashid, O.M.; Nagahashi, M.; Matsuyama, R.; Endo, I.; Takabe, K. The E2F pathway score as a predictive biomarker of response to neoadjuvant therapy in ER+/HER2breast cancer. Cells 2020, 9, 1643. [CrossRef]

10. Oshi, M.; Takahashi, H.; Tokumaru, Y.; Yan, L.; Rashid, O.M.; Matsuyama, R.; Endo, I.; Takabe, K. G2M cell cycle pathway score as a prognostic biomarker of metastasis in estrogen receptor (ER)-positive breast cancer. Int. J. Mol. Sci. 2020, 21, 2921. [CrossRef]

11. Pennisi, A.; Kieber-Emmons, T.; Makhoul, I.; Hutchins, L. Relevance of pathological complete response after neoadjuvant therapy for breast cancer. Breast Cancer Basic Clin. Res. 2016, 10, 103-106. [CrossRef] [PubMed]

12. Rosenberg, S.A.; Restifo, N.P.; Yang, J.C.; Morgan, R.A.; Dudley, M.E. Adoptive cell transfer: A clinical path to effective cancer immunotherapy. Nat. Rev. Cancer 2008, 8, 299-308. [CrossRef] [PubMed]

13. Stovgaard, E.S.; Nielsen, D.; Hogdall, E.; Balslev, E. Triple negative breast cancer-Prognostic role of immune-related factors: A systematic review. Acta Oncol. 2018, 57, 74-82. [CrossRef] [PubMed] 
14. Loi, S.; Sirtaine, N.; Piette, F.; Salgado, R.; Viale, G.; Van Eenoo, F.; Rouas, G.; Francis, P.; Crown, J.P.; Hitre, E.; et al. Prognostic and predictive value of tumor-infiltrating lymphocytes in a phase III randomized adjuvant breast cancer trial in node-positive breast cancer comparing the addition of docetaxel to doxorubicin with doxorubicin-based chemotherapy: BIG 02-98. J. Clin. Oncol. Off. J. Am. Soc. Clin. Oncol. 2013, 31, 860-867. [CrossRef]

15. Denkert, C.; Loibl, S.; Noske, A.; Roller, M.; Müller, B.M.; Komor, M.; Budczies, J.; Darb-Esfahani, S.; Kronenwett, R.; Hanusch, C.; et al. Tumor-associated lymphocytes as an independent predictor of response to neoadjuvant chemotherapy in breast cancer. J. Clin. Oncol. Off. J. Am. Soc. Clin. Oncol. 2010, 28, 105-113. [CrossRef]

16. Adams, S.; Gray, R.J.; Demaria, S.; Goldstein, L.; Perez, E.A.; Shulman, L.N.; Martino, S.; Wang, M.; Jones, V.E.; Saphner, T.J.; et al. Prognostic value of tumor-infiltrating lymphocytes in triple-negative breast cancers from two phase III randomized adjuvant breast cancer trials: ECOG 2197 and ECOG 1199. J. Clin. Oncol. Off. J. Am. Soc. Clin. Oncol. 2014, 32, 2959-2966. [CrossRef]

17. Tokumaru, Y.; Joyce, D.; Takabe, K. Current status and limitations of immunotherapy for breast cancer. Surgery 2020, 167, 628-630. [CrossRef]

18. Adams, S.; Loi, S.; Toppmeyer, D.; Cescon, D.W.; De Laurentiis, M.; Nanda, R.; Winer, E.P.; Mukai, H.; Tamura, K.; Armstrong, A.; et al. Pembrolizumab monotherapy for previously untreated, PD-L1-positive, metastatic triple-negative breast cancer: Cohort B of the phase II KEYNOTE-086 study. Ann. Oncol. Off. J. Eur. Soc. Med. Oncol. 2019, 30, 405-411. [CrossRef]

19. Schmid, P.; Adams, S.; Rugo, H.S.; Schneeweiss, A.; Barrios, C.H.; Iwata, H.; Diéras, V.; Hegg, R.; Im, S.A.; Shaw Wright, G.; et al. Atezolizumab and Nab-paclitaxel in advanced triple-negative breast cancer. N. Engl. J. Med. 2018, 379, 2108-2121. [CrossRef]

20. Schmid, P.; Cortes, J.; Pusztai, L.; McArthur, H.; Kümmel, S.; Bergh, J.; Denkert, C.; Park, Y.H.; Hui, R.; Harbeck, N.; et al. Pembrolizumab for early triple-negative breast cancer. N. Engl. J. Med. 2020, 382, 810-821. [CrossRef]

21. Takahashi, H.; Katsuta, E.; Yan, L.; Dasgupta, S.; Takabe, K. High expression of Annexin A2 is associated with DNA repair, metabolic alteration, and worse survival in pancreatic ductal adenocarcinoma. Surgery 2019, 166, 150-156. [CrossRef] [PubMed]

22. Asaoka, M.; Ishikawa, T.; Takabe, K.; Patnaik, S.K. APOBEC3-mediated RNA editing in breast cancer is associated with heightened immune activity and improved survival. Int. J. Mol. Sci. 2019, 20, 5621. [CrossRef] [PubMed]

23. Asaoka, M.; Patnaik, S.K.; Zhang, F.; Ishikawa, T.; Takabe, K. Lymphovascular invasion in breast cancer is associated with gene expression signatures of cell proliferation but not lymphangiogenesis or immune response. Breast Cancer Res. Treat. 2020, 181, 309-322. [CrossRef]

24. Katsuta, E.; Maawy, A.A.; Yan, L.; Takabe, K. High expression of bone morphogenetic protein (BMP) 6 and BMP7 are associated with higher immune cell infiltration and better survival in estrogen receptor-positive breast cancer. Oncol. Rep. 2019, 42, 1413-1421. [CrossRef] [PubMed]

25. Takeshita, T.; Asaoka, M.; Katsuta, E.; Photiadis, S.J.; Narayanan, S.; Yan, L.; Takabe, K. High expression of polo-like kinase 1 is associated with TP53 inactivation, DNA repair deficiency, and worse prognosis in ER positive Her2 negative breast cancer. Am. J. Transl. Res. 2019, 11, 6507-6521.

26. Takahashi, H.; Asaoka, M.; Yan, L.; Rashid, O.M.; Oshi, M.; Ishikawa, T.; Nagahashi, M.; Takabe, K. Biologically aggressive phenotype and anti-cancer immunity counterbalance in breast cancer with high mutation rate. Sci. Rep. 2020, 10, 1852. [CrossRef] [PubMed]

27. Tokumaru, Y.; Oshi, M.; Katsuta, E.; Yan, L.; Satyananda, V.; Matsuhashi, N.; Futamura, M.; Akao, Y.; Yoshida, K.; Takabe, K. KRAS signaling enriched triple negative breast cancer is associated with favorable tumor immune microenvironment and better survival. Am. J. Cancer Res. 2020, 10, 897-907.

28. Tokumaru, Y.; Katsuta, E.; Oshi, M.; Sporn, J.C.; Yan, L.; Le, L.; Matsuhashi, N.; Futamura, M.; Akao, Y.; Yoshida, K.; et al. High expression of miR-34a associated with less aggressive cancer biology but not with survival in breast cancer. Int. J. Mol. Sci. 2020, 21, 3045. [CrossRef]

29. Tokumaru, Y.; Asaoka, M.; Oshi, M.; Katsuta, E.; Yan, L.; Narayanan, S.; Sugito, N.; Matsuhashi, N.; Futamura, M.; Akao, Y.; et al. High expression of microRNA-143 is associated with favorable tumor immune microenvironment and better survival in estrogen receptor positive breast cancer. Int. J. Mol. Sci. 2020, 21, 3213. [CrossRef] 
30. Natividad, M.F.; Torres-Villanueva, C.A.; Saloma, C.P. Superantigen involvement and susceptibility factors in Kawasaki disease: Profiles of TCR V $\beta 2+$ T cells and HLA-DRB1, TNF- $\alpha$ and ITPKC genes among Filipino patients. Int. J. Mol. Epidemiol. Genet. 2013, 4, 70-76.

31. Chi, H.; Huang, F.Y.; Chen, M.R.; Chiu, N.C.; Lee, H.C.; Lin, S.P.; Chen, W.F.; Lin, C.L.; Chan, H.W.; Liu, H.F.; et al. ITPKC gene SNP rs28493229 and Kawasaki disease in Taiwanese children. Hum. Mol. Genet. 2010, 19, 1147-1151. [CrossRef] [PubMed]

32. Onouchi, Y.; Gunji, T.; Burns, J.C.; Shimizu, C.; Newburger, J.W.; Yashiro, M.; Nakamura, Y.; Yanagawa, H.; Wakui, K.; Fukushima, Y.; et al. ITPKC functional polymorphism associated with Kawasaki disease susceptibility and formation of coronary artery aneurysms. Nat. Genet. 2008, 40, 35-42. [CrossRef] [PubMed]

33. Kim, K.Y.; Bae, Y.S.; Ji, W.; Shin, D.; Kim, H.S.; Kim, D.S. ITPKC and SLC11A1 gene polymorphisms and gene-gene interactions in korean patients with Kawasaki disease. Yonsei Med. J. 2018, 59, 119-127. [CrossRef] [PubMed]

34. Yang, Y.C.; Chang, T.Y.; Chen, T.C.; Chang, S.C.; Chen, W.F.; Chan, H.W.; Lin, W.S.; Wu, F.T.; Lee, Y.J. Genetic polymorphisms in the ITPKC gene and cervical squamous cell carcinoma risk. Cancer Immunol. Immunother. CII 2012, 61, 2153-2159. [CrossRef] [PubMed]

35. Márquez, J.; Kohli, M.; Arteta, B.; Chang, S.; Li, W.B.; Goldblatt, M.; Vidal-Vanaclocha, F. Identification of hepatic microvascular adhesion-related genes of human colon cancer cells using random homozygous gene perturbation. Int. J. Cancer 2013, 133, 2113-2122. [CrossRef]

36. Gandhi, S.; Elkhanany, A.; Oshi, M.; Dai, T.; Opyrchal, M.; Mohammadpour, H.; Repasky, E.A.; Takabe, K. Contribution of immune cells to glucocorticoid receptor expression in breast cancer. Int. J. Mol. Sci. 2020, 21, 4635. [CrossRef]

37. Brown, T.J.; Crawford, S.E.; Cornwall, M.L.; Garcia, F.; Shulman, S.T.; Rowley, A.H. CD8 T lymphocytes and macrophages infiltrate coronary artery aneurysms in acute Kawasaki disease. J. Infect. Dis. 2001, 184, 940-943. [CrossRef]

38. Knudsen, E.S.; Witkiewicz, A.K. Defining the transcriptional and biological response to CDK4/6 inhibition in relation to ER+/HER2- breast cancer. Oncotarget 2016, 7, 69111-69123. [CrossRef]

39. Vincent-Salomon, A.; Rousseau, A.; Jouve, M.; Beuzeboc, P.; Sigal-Zafrani, B.; Fréneaux, P.; Rosty, C.; Nos, C.; Campana, F.; Klijanienko, J.; et al. Proliferation markers predictive of the pathological response and disease outcome of patients with breast carcinomas treated by anthracycline-based preoperative chemotherapy. Eur. J. Cancer 2004, 40, 1502-1508. [CrossRef]

40. Tordai, A.; Wang, J.; Andre, F.; Liedtke, C.; Yan, K.; Sotiriou, C.; Hortobagyi, G.N.; Symmans, W.F.; Pusztai, L. Evaluation of biological pathways involved in chemotherapy response in breast cancer. Breast Cancer Res. BCR 2008, 10, R37. [CrossRef]

41. Khor, C.C.; Davila, S.; Breunis, W.B.; Lee, Y.C.; Shimizu, C.; Wright, V.J.; Yeung, R.S.; Tan, D.E.; Sim, K.S.; Wang, J.J.; et al. Genome-wide association study identifies FCGR2A as a susceptibility locus for Kawasaki disease. Nat. Genet. 2011, 43, 1241-1246. [CrossRef] [PubMed]

42. Kuo, H.C.; Chang, W.C. Genetic polymorphisms in Kawasaki disease. Acta Pharmacol. Sin. 2011, 32, 1193-1198. [CrossRef] [PubMed]

43. Imboden, J.B.; Pattison, G. Regulation of inositol 1,4,5-trisphosphate kinase activity after stimulation of human T cell antigen receptor. J. Clin. Investig. 1987, 79, 1538-1541. [CrossRef] [PubMed]

44. Kim, J.H.; Jung, S.M.; Shin, J.G.; Cheong, H.S.; Seo, J.M.; Kim, D.Y.; Oh, J.T.; Kim, H.Y.; Jung, K.; Shin, H.D. Potential association between ITPKC genetic variations and Hirschsprung disease. Mol. Biol. Rep. 2017, 44, 307-313. [CrossRef]

45. Liu, J.; Lichtenberg, T.; Hoadley, K.A.; Poisson, L.M.; Lazar, A.J.; Cherniack, A.D.; Kovatich, A.J.; Benz, C.C.; Levine, D.A.; Lee, A.V.; et al. An integrated TCGA pan-cancer clinical data resource to drive high-quality survival outcome analytics. Cell 2018, 173, 400-416. [CrossRef]

46. Cerami, E.; Gao, J.; Dogrusoz, U.; Gross, B.E.; Sumer, S.O.; Aksoy, B.A.; Jacobsen, A.; Byrne, C.J.; Heuer, M.L.; Larsson, E.; et al. The cBio cancer genomics portal: An open platform for exploring multidimensional cancer genomics data. Cancer Discov. 2012, 2, 401-404. [CrossRef]

47. Chung, W.; Eum, H.H.; Lee, H.O.; Lee, K.M.; Lee, H.B.; Kim, K.T.; Ryu, H.S.; Kim, S.; Lee, J.E.; Park, Y.H.; et al. Single-cell RNA-seq enables comprehensive tumour and immune cell profiling in primary breast cancer. Nat. Commun. 2017, 8, 15081. [CrossRef] 
48. Hatzis, C.; Pusztai, L.; Valero, V.; Booser, D.J.; Esserman, L.; Lluch, A.; Vidaurre, T.; Holmes, F.; Souchon, E.; Wang, H.; et al. A genomic predictor of response and survival following taxane-anthracycline chemotherapy for invasive breast cancer. JAMA 2011, 305, 1873-1881. [CrossRef]

49. Shi, L.; Campbell, G.; Jones, W.D.; Campagne, F.; Wen, Z.; Walker, S.J.; Su, Z.; Chu, T.M.; Goodsaid, F.M.; Pusztai, L.; et al. The MicroArray Quality Control (MAQC)-II study of common practices for the development and validation of microarray-based predictive models. Nat. Biotechnol. 2010, 28, 827-838. [CrossRef]

50. Miyake, T.; Nakayama, T.; Naoi, Y.; Yamamoto, N.; Otani, Y.; Kim, S.J.; Shimazu, K.; Shimomura, A.; Maruyama, N.; Tamaki, Y.; et al. GSTP1 expression predicts poor pathological complete response to neoadjuvant chemotherapy in ER-negative breast cancer. Cancer Sci. 2012, 103, 913-920. [CrossRef]

51. Oshi, M.; Katsuta, E.; Yan, L.; Ebos, J.M.L.; Rashid, O.M.; Matsuyama, R.; Endo, I.; Takabe, K. A novel 4-gene score to predict survival, distant metastasis and response to neoadjuvant therapy in breast cancer. Cancers 2020, 12, 1148. [CrossRef] [PubMed]

52. Aran, D.; Hu, Z.; Butte, A.J. xCell: Digitally portraying the tissue cellular heterogeneity landscape. Genome Biol. 2017, 18, 220. [CrossRef] [PubMed]

53. Subramanian, A.; Tamayo, P.; Mootha, V.K.; Mukherjee, S.; Ebert, B.L.; Gillette, M.A.; Paulovich, A.; Pomeroy, S.L.; Golub, T.R.; Lander, E.S.; et al. Gene set enrichment analysis: A knowledge-based approach for interpreting genome-wide expression profiles. Proc. Natl. Acad. Sci. USA 2005, 102, 15545-15550. [CrossRef] [PubMed]

54. Liberzon, A.; Birger, C.; Thorvaldsdóttir, H.; Ghandi, M.; Mesirov, J.P.; Tamayo, P. The Molecular Signatures Database (MSigDB) hallmark gene set collection. Cell Syst. 2015, 1, 417-425. [CrossRef]

55. Okano, M.; Oshi, M.; Butash, A.L.; Asaoka, M.; Katsuta, E.; Peng, X.; Qi, Q.; Yan, L.; Takabe, K. Estrogen receptor positive breast cancer with high expression of androgen receptor has less cytolytic activity and worse response to neoadjuvant chemotherapy but better survival. Int. J. Mol. Sci. 2019, 20, 2655. [CrossRef] [PubMed]

56. Okano, M.; Oshi, M.; Butash, A.L.; Katsuta, E.; Tachibana, K.; Saito, K.; Okayama, H.; Peng, X.; Yan, L.; Kono, K.; et al. Triple-negative breast cancer with high levels of annexin A1 expression is associated with mast cell infiltration, inflammation, and angiogenesis. Int. J. Mol. Sci. 2019, 20, 4197. [CrossRef]

57. Katsuta, E.; Yan, L.; Takeshita, T.; McDonald, K.A.; Dasgupta, S.; Opyrchal, M.; Takabe, K. High MYC mRNA expression is more clinically relevant than MYC DNA amplification in triple-negative breast cancer. Int. J. Mol. Sci. 2019, 21, 217. [CrossRef]

58. Takahashi, H.; Kawaguchi, T.; Yan, L.; Peng, X.; Qi, Q.; Morris, L.G.T.; Chan, T.A.; Tsung, A.; Otsuji, E.; Takabe, K. Immune cytolytic activity for comprehensive understanding of immune landscape in hepatocellular carcinoma. Cancers 2020, 12, 1221. [CrossRef]

59. Takahashi, H.; Oshi, M.; Asaoka, M.; Yan, L.; Endo, I.; Takabe, K. Molecular biological features of nottingham histological grade 3 breast cancers. Ann. Surg. Oncol. 2020. [CrossRef]

60. Katsuta, E.; Rashid, O.M.; Takabe, K. Fibroblasts as a biological marker for curative resection in pancreatic ductal adenocarcinoma. Int. J. Mol. Sci. 2020, 21, 3890. [CrossRef]

61. Takahashi, H.; Katsuta, E.; Yan, L.; Tokumaru, Y.; Katz, M.H.G.; Takabe, K. Transcriptomic profile of lymphovascular invasion, a known risk factor of pancreatic ductal adenocarcinoma metastasis. Cancers 2020, 12, 2033. [CrossRef] [PubMed]

(C) 2020 by the authors. Licensee MDPI, Basel, Switzerland. This article is an open access article distributed under the terms and conditions of the Creative Commons Attribution (CC BY) license (http://creativecommons.org/licenses/by/4.0/). 